\title{
Do Hermetic Storage Technology Significantly Abate Losses of Rice Over Time? An Economic Evaluation
}

\author{
Mohammad Afzal Hossain ${ }^{1 *}$, Md. Abdul Awal', Md. Monjurul Alam², Md. Rostom Ali², Fakir Azmal \\ Huda $^{3}$, and Afruz Zahan ${ }^{1}$
}

${ }^{1}$ Bangladesh Rice Research Institute, Gazipur 1701, Bangladesh; ${ }^{2}$ Department of Farm Power and Machinery, Bangladesh Agricultural University, Mymensingh 2202, Bangladesh; and ${ }^{3}$ Department of Agricultural Economics, Bangladesh Agricultural University, Mymensingh 2202, Bangladesh.

*Correspondence: engr.afzal@yahoo.com (Dr. Mohammad Afzal Hossain, Senior Scientific Officer, Bangladesh Rice Research Institute, Gazipur 1701, Bangladesh).

\begin{abstract}
In Bangladesh, traditional technologies like Dole, Auri, Bamboo Gola, Motka, and Plastic bag are widely used in rice storage. Hot and humid weather of the country favors the growth of insects in these which are not functional for rice storage. Recently, hermetic bag (HB) GrainPro and PICS bags are suggested for rice storage without being subjected to economic analysis in the country. Very few empirical studies on the economic analysis of storage technologies were conducted at laboratory and field conditions. In it, losses of rice storage using traditional technologies and $\mathrm{HB}$ were evaluated to judge the economic effects of these. Moreover, determinants of storage benefit were analyzed for different devices and econometric modeling was formulated to have the understanding the benefit of reduced loss by storage over time. These benefits were found to increase with time meaning that a farmer gained more benefit by storing longer period in HB. Results showed that economically feasible and attractive in investing these technologies at a discount rate of 12 percent by using financial analytical tools like net present value (NPV) and benefit-cost ratio (BCR) of different storage technologies. The results also indicate that gain of storage clearly increased over time. Considering BCR, Plastic drum use in rice storage is the most profitable storage technology followed by GrainPro and PICS Bag for consumption. Regression analysis of treatment and time effect of storage indicated that percentage profit per month is found the highest in GrainPro bag followed by PICS bag, Dole, Plastic bag and Motka, respectively. Promotion of PICS and GrainPro bags in rice seed storage would be more cost-effective and economically feasible to farmers.
\end{abstract}

Keywords: Storage technology, PICS bag, Economic analysis, Feasible, Evaluation, Abate, and Loss reduced.

\section{INTRODUCTION:}

In recent years, there has been increasing promotion of hermetic grain storage devices in Asia and Africa (De Groote et al., 2013). Bangladesh, the fourth largest rice producer in the world (FAO, 2010). Rice is the staple food and counted as 93 percent of the total food produced in Bangladesh (Hossain, 2020). A considerable UniversePG I www.universepg.com amount of rice grain is lost in each stage of its production, processing and storage rising to as high as 25 percent. Post-harvest activities particularly drying and storing of rice are performed by small-holding women farmers for the purposes of preservation of seed and food grain using traditional storage structures Dole, Motka, Plastic bag/drum and Gunny bag for sale and 
seed purposes (Hossain et al., 2017). There are about eight different types of traditional technologies for storage of rice is used at farm level in Bangladesh. Among these, Dole, steel drum and Motka are common (Hossain, 2019). However, these are not effective in rice storing are subjected to damage due to biological, environmental and other factors. In-store loss of rice is higher (19.7 percent) in Bangladesh compared to other countries where storage systems are better. Out of which 12-13 percent loss was caused by insects and rodents. These loss figures were confirmed by a World Bank study on commercial rice storage in Bangladesh as reported by FAO Corporate Document Repository (FAO, 2004; Hossain et al., 2020).

In Bangladesh, average in-store losses occurred for Aus, Aman and Boro rice were 3.68, 3.80 and 4.12 percent, respectively with the aggregated average being 3.92 percent. The average in-store losses of rice in large, medium, small and marginal farmers were 4.48, 3.92, 4.0 and 3.59 percent, respectively (Abedin et al., 2012). Storage loss of rice in Brazil is 2.4 percent; in Asia is ranged from 2-6 percent (FAO, 2004). When rice is stored in sacks the losses were 3.5-6 percent in India, 3-5 percent in Nepal, 2-3 percent in the Philippines, 5 percent in Thailand. These damages are caused mainly by rodents as reported in these countries. WeiFen et al., (2003) in China found that grain storage loss was about 0.2 percent at national reserve level but 7-13 percent was in rural household level. Abedin et al. (1999) studied for rough rice storage and found woven bamboo and Dole were as the most suitable low-cost conventional storage technologies. Mia et al. (2007) observed, Dole, Motka, Jala, Steel drum, Plastic and Gunny bags are used rice storage in Bangladesh and loss of it was found 2.33 percent. Considering capital cost, expected life and storage loss, Steel drum, Gunny and Plastic bags, Motka or Jala were found more economical. Brown rice was stored in two traditional woven bamboo storage technologies, Berh and Dole, with and without polythene lining. The polythene lining of the bins caused little resistance to flow of heat and slightly less moisture accumulation from the ambient air, but this had no significant effect on germination capacity and insect infestation. Seed grains should not be stored under airtight conditions as this result in viability loss (Ullah and Abedin, 1991). Bhuiyan et al.
(2006) got the highest viability of stored rice in Plastic drum. HB i.e., PICS and Grain Probags have emerged as an alternative of traditional storage that is suitable for storage of rice to preserve germination potential 85 percent or more for the periods up to 9 months. In jute bag, germination of it reduces down by 14 percent to 76 percent within 3 months (Omondi et al., 2011).

PICS bag is a simple, low-cost triple bagging technology evaluated for maize storage mainly in West Africa (Baoua et al., 2016). The three layers include an outer polypropylene bag and two inner linings of high density polyethylene (HDPE). Trials showed that PICS bag can be used for maize storage even in areas with high prevalence of larger grain borer, but storage of maize should begin soon after harvest and drying to minimize bag damage that can occur when very large numbers of larger grain borers are present (Baoua et al., 2016). GrainPro bag is still new in Bangladesh. The bag consists of an outer polypropylene bag with an inner high-density polyethylene (HDPE) lining. Famers can buy only the inner lining from GrainPro and using it with their normal bags since the inner lining is the tool that maintains air tightness while in storage. Grain Probag was found effective under artificial in-festation although they were perforated by LGB (De Groote $e t$ al., 2013). PICS and GrainPro Bag with cow-peas storage were found similarly effective. Farmers can choose either of two bags, taking into account price, availability and durability (Baoua et al., 2016).

In Bangladesh, rice storage in GrainPro and PICS bag were found better considering storage period, weight loss, and minimum damage to insects' infestation than that traditional technologies i,e. Dole, Motka, Plastic drum, and Plastic bag (Hossain, 2020). Few researches/ studies conducted earlier on benefits of hermetic bag in Philippine, Mexico, Tanjania and found better in their climate context. Hot humid weather of Bangladesh favors rapid insect infestation. No studies have been found in Bangladesh regarding the feasibility of hermetic bag over traditional technologies. These storage technologies are available in Bangladesh. Adoption of HB does not guarantee sustainability unless it produces more profit than the existing technology. Potential demand for a technology requires a careful analysis of the local market to determine if the technology is profitable for farmers. Comprehensive eco- 
nomic analysis needs to be performed to determine losses and benefits of using the new technology compared to the existing technology. The study was conducted to determine the economically viable options of $\mathrm{HB}$ use for farmers in Bangladesh.

\section{METHODOLOGY:}

2.1. Laboratory trial - The trial was conducted in the postharvest preservation and processing laboratory, Bangladesh Agricultural University (BAU), Mymensingh in completely randomized design (CRD) with three replications and six treatments as shown in Table 1. One of these treatments, Motka was used without pesticide as the control.

2.2. On-farm trail - The experiment was conducted at randomized complete block design at two locations i.e. Phulpur of Mymensingh and Shymgonj of Netrokona districts of Bangladesh. Ten farmers from each village and 4 villages from each location were taken to assess hermetic bags economically over traditional storage technologies.

2.3. Data collection - Daily temperature and relative humidity of the storage room were measured using dry and wet bulb thermometer (Zeal, UK). Digital moisture meter, Moisture Check PLUS ${ }^{\mathrm{TM}}$, SW08120 was used to measure moisture content of rice. Germination of rice was calculated on sand media in plastic box following the International Seed Testing Rules (ISTA, 1999). Weight and storage loss of stored rice was calculated using count and weigh method (Adams \& Schulten, 1978; Boxall, 2002; Boxall, 1986; Ratnadass and Fleurat-Lessard, 1991). Possible loss reduction of paddy was measured using hermetic bags over traditional storage technologies. Benefit cost analysis was done to estimate economic viability of investment in these technologies. The following parameters were taken from the used treatments as shown in Table 1.

2.4. Measurement of present worth - Economic analysis (Gittinger, 1982) was done in order to determine the viability of the different storage technology in rice storage options. Since investment involves a future stream of costs and benefits, it must be discounted to find their present worth. Net present value (NPV) represents the present worth of the income stream generated by an investment (in this case the storage technology to the farmer). Benefit cost ratio (BCR) UniversePG I www.universepg.com represents the present worth of the benefit stream divided by the present worth of the cost stream. To determine BCR and NPV the following formula were used. BCR of paddy storage technologies for consumption and seed purposes was calculated. If benefit is considered for total life span of the technology taken into BCR calculation that is discounted BCR.

Table 1: Treatments and parameters of data collection

\begin{tabular}{|c|c|}
\hline Treatments & Parameters \\
\hline $\mathrm{T}_{1}=$ Dole & Moisture Content (percent) \\
$\mathrm{T}_{2}=$ Motka & Temperature $\left({ }^{\circ} \mathrm{C}\right)$ \\
$\mathrm{T}_{3}=$ Plastic Drum & Relative Humidity (percent) \\
$\mathrm{T}_{4}=$ GrainPro Bag & Insect Infestation (percent) \\
$\mathrm{T}_{5}=$ PICS Bag & Germination (percent) \\
$\mathrm{T}_{6}=$ Plastic Bag & Price $(\mathrm{Tk} / 40 \mathrm{~kg})$ \\
\hline
\end{tabular}

Net present value $(\mathrm{NPV})=\sum_{t=1}^{t=n} \frac{B_{t}-C_{t}}{(1+i)^{t}}$

Benefit cost ratio $(\mathrm{BCR})=\frac{\sum_{t=1}^{t=n} \frac{B_{t}}{(1+i)^{t}}}{\sum_{t=1}^{t=n} \frac{C_{t}}{(1+i)^{t}}}$

Were,

$$
\begin{aligned}
& B_{t}=\text { Total benefit }(\mathrm{Tk} / \mathrm{ha}) \text { in } \mathrm{t}^{\text {th }} \text { year. } \\
& \mathrm{C}_{\mathrm{t}}=\text { Total cost }(\mathrm{Tk} / \mathrm{ha}) \text { in } \mathrm{t}^{\text {th }} \text { year. } \\
& \mathrm{t}=\text { Number of years } \\
& \mathrm{i}=\text { Interest (discount) rate. }
\end{aligned}
$$

2.5. Econometric modeling - The effect of treatment and storage duration on storage loss was analyzed based on the following model (Gittinger, 1982):

$Y=\alpha+\beta_{0} t_{0} T_{1}+\beta_{1} t_{1} T_{1}+\beta_{2} t_{2} T_{1}+\beta_{3} t_{3} T_{1}+\beta_{4} t_{4} T_{1}+\beta_{5} t_{5} T_{1}+$ $\beta_{6} t_{6} T_{1}+\beta_{0} t_{0} T_{2}+\beta_{1} t_{1} T_{2}+\beta_{2} t_{2} T_{2}+\beta_{3} t_{3} T_{2}+\beta_{4} t_{4} T_{2}+\beta_{5} t_{5} T_{2}+$ $\beta_{6} t_{6} T_{2}+\beta_{0} t_{0} T_{3}+\beta_{1} t_{1} T_{3}+\beta_{2} t_{2} T_{3}+\beta_{3} t_{3} T_{3}+\beta_{4} t_{4} T_{3}+\beta_{5} t_{5} T_{3}+$ $\beta_{6} \mathrm{t}_{6} \mathrm{~T}_{3}+\ldots \ldots \ldots \beta_{6} \mathrm{t}_{6} \mathrm{~T}_{6}$.

Where,

$\mathrm{t}$ is time, $\alpha=$ constant, $\beta=$ co-efficient $\& \mathrm{~T}$ is treatment.

The right side of the equation therefore represents a matrix of cross effects of each treatment with time. Since percentage loss is not expected at time zero, estimation of the model was done without including an intercept using STATA.

2.6. Financial analysis of storage technologies - The purchase price of paddy was Tk 520 per $40 \mathrm{~kg}$ before storage. Price of paddy depends on moisture content, 
insect infestation of it. It was analyzed monthly. HB and traditional technologies are being stored with paddy at $12 \%$ moisture content. Value addition and financial loss were calculated of stored paddy in case of all storage technologies (Gittinger, 1982).

\section{Gross return and net return of farmer's}

Gross return was calculated by multiplying the total volume of output of an enterprise by the average price of the product. The following equation was used to estimate gross return:

$$
\mathbf{G R}=\Sigma \mathbf{Q P} . \mathbf{P P}
$$

Where,

$\mathrm{GR}=$ Gross return from rice seed (Tk/ha)

$\mathrm{QP}=$ Quantity of rice seed (ton)

$\mathrm{PP}=$ Average price of rice seed (Tk/ton)

Net return was calculated by deducting all costs (variable and fixed) from gross return.

$\pi=$ Gross return $-($ variable cost + fixed cost $)$

Here, $\pi=$ Net return (profit)

\section{Marketing margin received by actors}

Marketing margin is the difference between the producers' and consumers' prices. Marketing mar-gins and net margins of different intermediaries were estimated by using the following formula:
Gross marketing margin $(\mathrm{Tk} / \mathrm{ton})=$ Sale price $(\mathrm{Tk} / \mathrm{ton})$ - Purchase price (Tk/ton)

Net margin $(\mathrm{Tk} / \mathrm{ton})=$ Gross margin $(\mathrm{Tk} / \mathrm{ton})-$ Marketing cost $(\mathrm{Tk} / \mathrm{ton})$

Value addition $(\%)=$ (Marketing margin/Purchase price) $\mathrm{x} 100$

\section{RESULTS:}

3.1 Analysis of discounted cost and benefits of different storage technologies - The cost for Grainer and PICS bags was TK. 250 and 600. Average price of paddy was Tk. 13/kg, and farmers store for four to six months per season. Hermetic bags gave BCR 1.73 which indicated that the farmer can recover capital within a year using it. It also indicates that hermetic bags are economically viable even if these used for one season only. The economic viability is expected to increase with increased length of storage, higher grain prices, and when the bag is re-used for subsequent seasons. Re-using a hermetic bag for three years the BCR raises to 5.89 (Table 2). This implies that farmers need to take care of $\mathrm{HB}$ and ensure use of that for multiple seasons. They need to store paddy longer and sell when the demand is high and supply is low to draw higher prices. Hence, most benefit could come from the technology.

Table 2: NPV (Tk) and BCR over an investment period of 3 years

\begin{tabular}{|c|c|c|c|c|c|c|c|}
\hline & Year & Dole & Motka & Plastic Bag & Plastic Drum & GrainPro Bag & PICS Bag \\
\hline & 0 & 238 & 209 & 171 & 878 & 1026 & 1038 \\
\hline & 1 & 212.50 & 186.61 & 152.68 & 783.93 & 916.07 & 926.79 \\
\hline & 2 & 189.73 & 166.61 & 136.32 & 699.94 & 817.92 & 827.49 \\
\hline & 3 & 169.40 & 148.76 & 121.71 & 624.94 & 730.29 & 738.83 \\
\hline NPV at year1 & 450.50 & 209.00 & 171.00 & 878.00 & 1026.00 & 1038.00 \\
\hline NPV at year1 & 640.23 & 562.22 & 460.00 & 2361.86 & 2759.99 & 2792.27 \\
\hline NPV at year1 & 809.64 & 710.98 & 581.71 & 2986.81 & 3490.28 & 3531.10 \\
\hline Purchase Price (Tk) & 600.00 & 300.00 & 30.00 & 450.00 & 250.00 & 600.00 \\
\hline BCR at year1 & 0.75 & 0.70 & 5.70 & 1.95 & 4.10 & 1.73 \\
\hline BCR at year2 & 1.07 & 1.87 & 15.33 & 5.25 & 11.04 & 4.65 \\
\hline BCR at year3 & 1.35 & 2.37 & 19.39 & 6.64 & 13.96 & 5.89 \\
\hline
\end{tabular}

3.2. Cross effect of different storage period and technologies - Results, after regressed the percent profit/loss with the cross effects of the treatment and time (Simon et al., 2010), are depicted in Table 3. As such, the coefficients are to be interpreted as profit/loss, in percent of initial quantity, per month. The coefficients are found positive and significant for Motka (control) and HB. Hence, profit per month is 4.63, 8.19, 7.60, 5.01 and 6.57 percent for the control Motka, PICS 
bag, GrainPro bag, Plastic bag and for Dole, respectively.

3.3. Value addition of paddy - Storing paddy in HB i.e., GrainPro and PICS bags rather than traditional technologies such as Dole, Motka, Plastic drum and Plastic bag, farmers can earn additional value over sale just after harvesting. The least amount of value addition
(Tk 3,350/ton) was obtained in Motka followed by Plastic bag, Dole and Plastic drum (Tk 6,425/ton) storing paddy for con-sumption purpose (Fig 1). From (Fig 1.b), it is clear that highest amount of value addition (Tk 61,000/ton) can be obtained using PICS bag followed by GrainPro bag (Tk 60,000/ton) and Plastic drum (Tk 29,750/ton) in paddy seed purpose.

Table 3: Regression over time, cross effects with the different treatments

\begin{tabular}{|c|c|c|c|}
\hline Cross Effect of Time with Treatments & Coefficient & Std. Error & P Value \\
\hline Dole & $6.573053^{*}$ & 0.4934 & 0.000 \\
\hline Motka & $4.637896^{*}$ & 0.5643 & 0.000 \\
\hline Plastic Bag & $5.016941^{*}$ & 0.5045 & 0.000 \\
\hline Plastic Drum & $6.89765^{*}$ & 0.5463 & 0.000 \\
\hline GrainPro Bag & $7.600549^{*}$ & 0.5546 & 0.000 \\
\hline PICS Bag & $8.19881^{*}$ & 0.6097 & 0.000 \\
\hline R Square & 0.4361 & & \\
\hline N & 526 & & \\
\hline
\end{tabular}

$* 1 \%$ level of significance

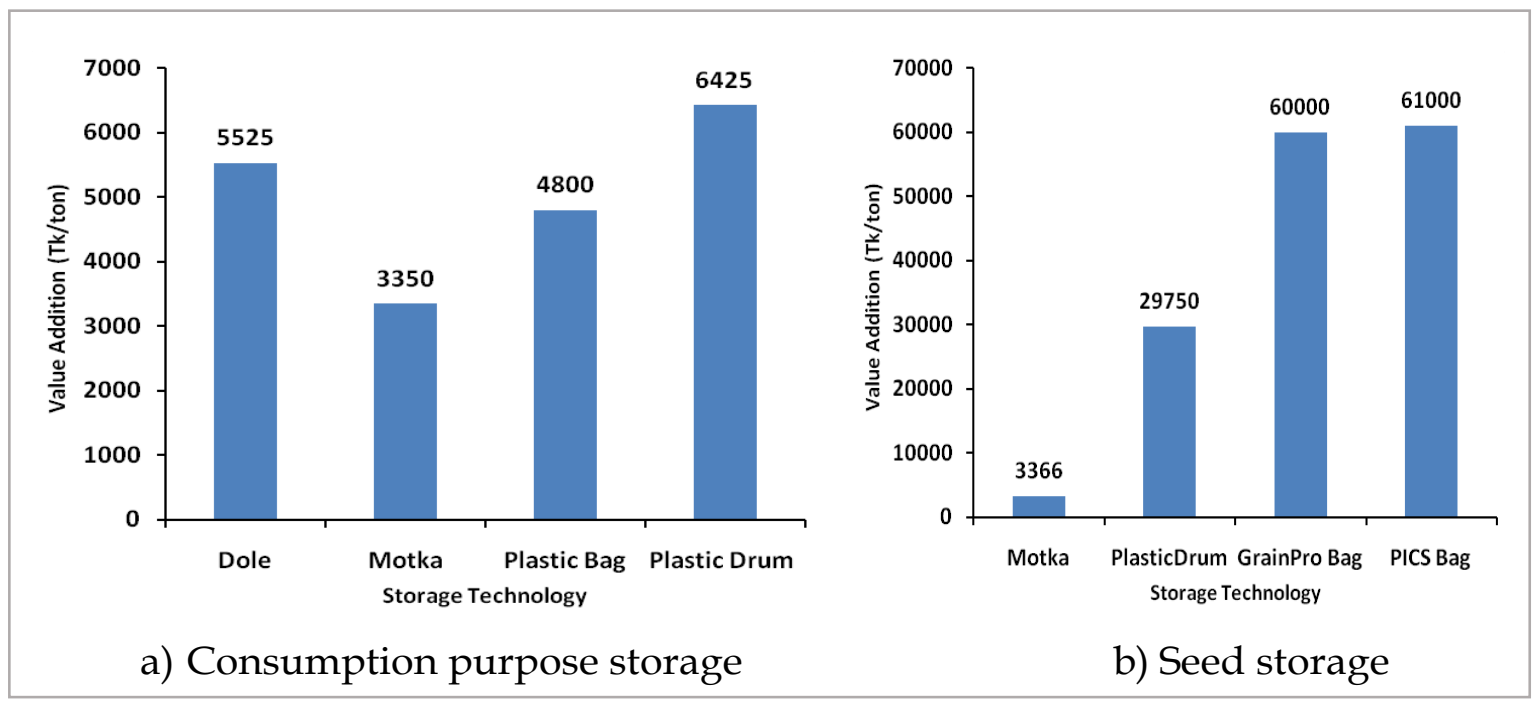

Fig 1: Value addition of stored paddy in different storage technologies.

3.4. Benefit cost ratio of paddy storage technology For consumption purposes storage, Plastic bag was found the least expensive storage technology followed by Motka and Dole, respectively (Table 4). Highest net financial benefit was obtained using Plastic drum (Tk $5.97 / \mathrm{kg}$ ) followed by Plastic bag, Dole and Motka (Tk $1.76 / \mathrm{kg}$ ). The highest BCR was found in Plastic drum (24.43) in storing paddy followed by Dole, Plastic bag and Motka (7.19). Farmer gets return of investment after 3 months of storage in Plastic bag followed by Dole, Plastic drum, and Motka (68 months). In seed storage, the highest net benefit (TK. 63.3/kg) was obtained using PICS bag followed by GrainPro bag, Plastic drum and Plastic bag as shown in Table 5. Considering benefit cost ratio (BCR), Plastic drum use in seed storage is the most profitable (35.6) storage technology followed by GrainPro and PICS bag, respectively. The least amount of payback period was obtained using Plastic bag (0.3 month) in paddy seed storage followed by GrainPro, PICS bag and Plastic drum (2.07 month). 
Table 4: Cost comparison of paddy storage technologies for consumption purpose

\begin{tabular}{ccccc}
\hline Item & Dole & Motka & Plastic Bag & Plastic Drum \\
\hline Purchase price (Tk/each) & 1200 & 500 & 40 & 500 \\
\hline Capacity (kg) & 500 & 50 & 50 & 50 \\
\hline Storage cost (Tk/yr/kg) & 3.77 & 3.24 & 2.29 & 3.04 \\
\hline Sale price (Tk/kg) & 22 & 20 & 21 & 24 \\
\hline Gross return (Tk/ton) & 20680 & 18686 & 20000 & 23729 \\
\hline Net Benefit (Tk/kg) & 3.22 & 1.76 & 3.70 & 5.97 \\
\hline BCR & 11.69 & 7.19 & 7.67 & 24.43 \\
\hline Pay Back Period (month) & 9 & 68 & 3 & 20 \\
\hline
\end{tabular}

Table 5: Cost comparison of paddy storage technologies for seed purpose

\begin{tabular}{cccccc}
\hline Item & Motka & Plastic Bag & Plastic Drum & GrainPro Bag & PICS Bag \\
\hline Purchase price (Tk/Each) & 500 & 40 & 500 & 300 & 350 \\
\hline Capacity (kg) & 50 & 50 & 50 & 50 & 50 \\
\hline Storage cost (Tk/yr/kg) & 6.74 & 5.58 & 6.06 & 2.35 & 1.70 \\
\hline Sale price (Tk/kg) & 25.0 & 35.0 & 50 & 80.0 & 80.0 \\
\hline Gross return (Tk/ton) & 2335.8 & 3333 & 4944 & 7988 & 7996 \\
\hline Net benefit of storage (Tk/kg) & 3.3 & 14.4 & 28.9 & 62.6 & 63.3 \\
\hline Net benefit per ton (Tk) & 3300 & 14400 & 28900 & 62600 & 63300 \\
\hline BCR & 4 & 6.9 & 35.6 & 26 & 23 \\
\hline Pay Back Period (Months) & 37 & 0.3 & 2 & 0.6 & 0.7 \\
\hline
\end{tabular}

3.5. Storage loss reduction of paddy - HB followed the expected trend with oxygen levels falling sharply below $10 \%$ and carbon dioxide in-creasing to almost $10 \%$ after12 weeks hence resulting in insect death, storage and germination loss of paddy (Mutambuki et al. 2019). Paddy remained insects free. Loss of stored rice can be reduced by 6.52 percent using PICS bag followed by GrainPro Bag, Plastic drum, Plastic Bag and Dole (0.57 percent), respectively (Fig 2). Highest amount of storage loss can be reduced using HB followed by Plastic drum. And the least amount of loss is possible to reduce storing rice in Plastic bag followed by traditional Dole over Motka.

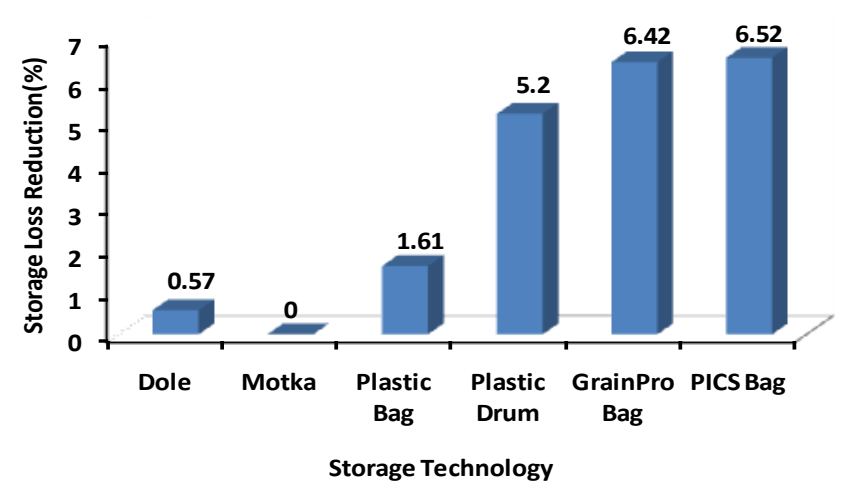

Fig 2: Storage loss reduction of paddy.

\section{CONCLUSION:}

Hermetic bag appeared as a feasible option for rice storage in Bangladesh to prevent storage loss, maintain seed quality and increase economic return for farm house holder. It provides small householder food security ensuring year-round consumption and quality seed to farmers. HB can reduce the fluctuation of year round market supply, maintain fair price of rice to consumers and create scope of seed business as income generation. Storage loss $(6 \%)$ which is equivalent to 1,200 Tk/ton can be reduced using PICS bag followed by Grain Probag and Plastic drum. For consumption purpose storage, Plastic Bag was found the least expensive technology followed by Motka and Dole, respectively and in seed storage, PICS Bag followed by GrainPro bag, Plastic drum and Plastic bag. Farmer can get return of investment storing rice within least possible time in GrainPro bag followed by PICS bag and Plastic drum for seed storage; Plastic bag followed by Dole and Plastic drum for consumption purpose storage. Considering benefit cost ratio, Plastic drum is more attractive to farmers for dual purposes. As per storage cost, PICS bag followed by GrainPro bag, Plastic bag and Plastic drum for seed; and Plastic bag 
followed by Plastic drum is preferable to farmers for consumption purpose storage. Hermetic bag should be promoted at farm level to strengthen food security. These technologies will reach more farmers and possibly at lower prices if more brands are available in the local market. In achieving these benefits, HB should be developed locally. However, PICS bag was the better storage device than existing technologies for its higher benefits i.e. the least percentage of value, storage and germination and moisture loss.Moreover, training for extension workers and farmers needed to ensure that the bags can be used widely.

\section{ACKNOWLEDGEMENT:}

This research was performed as part of PHLIL project "USAID Post-Harvest Loss Reduction Innovation Lab-Bangladesh Component" funded by the USAID and ADM Institute for the Prevention of Post-Harvest Loss, University of Illinois, USA (Grant Number: UReRA 2015-05296-01-00).

\section{CONFLICTS OF INTEREST:}

We declare no single potential conflict of interest.

\section{REFERENCES:}

1) Abedin, M. Z., Hossain, M. D., Choudhury, M. A. and Ahamed, T. (1999). Rough-rice storage in wove bamboo container (Dole). Bangladesh J. of Progressive Agriculture, 10(1\&2): 79-82.

2) Abedin, M. Z., M. Z. Rahman M. I. A. Mia and. Rahman K. M. M. (2012). In-store losses of rice and ways of reducing such losses at farmers' level: An assessment in selected regions of Bangladesh, J. Bangladesh Agril. Univ. 10(1): 133-144. https://www.banglajol.info/index.php/JBAU/article/v iew/12105

3) Adams, J.M. and G.G.M. Schulten, (1978). Losses Caused by Insects, Mites and Microorganisms. In: Postharvest Grain Loss Assessment Methods, Harris, K.L. and C.J. Lindblad (Eds.). American Association of Cereal Chemists, St. Paul MN., pp: 83-95.

4) Baoua I.B.; Amadou L.; Bakoye O.; Baributsa D.; Murdock L.L. (2016). Triple bagging hermetic technology for post-harvest preservation of paddy rice Oryza sativa L. in the Sahel of
West Africa, J. of Stored Products Research $\mathbf{6 8}$ (2016) 73-79.

\section{https://doi.org/10.1016/j.jspr.2016.04.006}

5) Bhuiyan, M. G. K., Quasem, M. A. Baqui, M. A., Rahman, M. A., and Rahman, S. M. M. (2006). A comparative on study the quality of paddy seed stored in different storage structure.

6) Boxall, R. A. (2002). Damage and Loss Caused by the Larger Grain Borer Prostephanus truncatus. Integrated Pest Management Revi.s, 7(2):105-121. https://link.springer.com/article/10.1023/A:10263971 $\underline{15946}$

7) Boxall, R.A. (1986). A Critical Review of the Methodology for Assessing Farm-level Grain Losses after Harvest. Slough, U.K.: Tropical Development and Research Institute. ISBN: 0 85954-208-4.

https://gala.gre.ac.uk/id/eprint/10793/

8) De Groote, (2013). Effectiveness of metal silos and super grain bags in controlling maize storage pests in Kenya.

9) FAO, (2010). 'Food Outlook: Global Market Analysis', Global Information and Early Warning System, An internet version, Pp 1-119.

http://www.fao.org/3/al969e/al969e00.pdf

10) Gittinger, J. P. (1982). Economic Analysis of Agricultural Projects. Washington DC: The World Bank, Report Number, UNN76.

https://documents1.worldbank.org/curated/en/584961 468765021837/pdf/multi0page.pdf

11) Hossain, M.A., Awal, M.A., and Ali, M.R., (2017). Paddy storage facilities and prevalence of insect at farmhouses in Bangladesh.

12) Hossain SM, Sarker C, Alam MM, Chowdhury KB, and Kamal MG. (2020). Investigation of vegetable market integration system in Dhaka city: a study on effective supply value chain analysis, Int. J. Manag. Account. 2(6), 131-146.

https://doi.org/10.34104/ijma.020.01310146

13) Hossain, M., Awal, M., Ali, M., and Alam, M.M. (2019). Efficacy of diversified rice storage technologies in Bangladesh. Progressive Agriculture, 30, 51-56. https://doi.org/10.3329/pa.v30i0.41557

14) Hossain, M.A. (2020). Appropriate Paddy Storage for Small Farmers in Bangladesh. PhD Thesis Approved to the Department of Farm Power and Machinery, Bangladesh Agricultural University, Mymensingh, Bangladesh. 
15) International Seed Testing Association, (ISTA), (1999). International Rules for Seed Testing. Seed Science and Technology, 27, Supplement, pp333. https://www.cabi.org/isc/abstract/19990307875

16) Kabir MA, Shabbir MSA, Ealahi AHMF, (2014). International Conference on Mechanical, Industrial and Energy Engineering, 26-27 December, 2014 "Feasibility Study on Power Generation in Bangladesh using Rice Husk as an Alternative Source of Fuel".

17) Mia, M. I. A, Alam, M.S., Ali, M. A. and Abedin, M. Z. (2007). Study on grain storage facilities as food security measure in flood prone areas of Bangladesh. Progressive Agriculture, 18(2), 223233. https://doi.org/10.3329/pa.v18i2.18244

18) Omondi, B.A., J. Nanqing, J. Van Den Berg and F. Schulthess, (2011). The flight activity of Prostephanus truncates (Horn) (Coleoptera: Bostrichidae) and Teretriusnigrescens Lewis (Coleop- tera: Histeridae) in Kenya. J. Stored Products Res., 47(1): 13-19.

19) Ratnadass, A., and Fleurat-Lessard, F. (1991). Improvements in the practical methods of assessment of losses caused by insects in grain stored at the village level in tropical Africa in $5^{\text {th }}$ International Working Conference on Stored-Product Protection, edited by F.-L. F. and Ducom, P. Bordeaux, France.

http://spiru.cgahr.ksu.edu/proj/iwcspp/iwcspp5.html

20) Ullah, M. W., and Abedin, M. Z. (1991). Effect of moisture on rough rice stored in open and airtight containers. Bangladesh Journal of Agricultural Sciences, 18(1): 143-148.

21) WeiFen, Q. and ZuXun, J. (2003). Rice storage in China. Dept. of Science \& Technology, Chinese Cereals \& Oil Association, Nanjing Univ. of Economics, 128 Tie BeiJie, Nanjing 210003, China.

Citation: Hossain MA, Awal MA, Alam MM, Ali MR, Huda FA, and Zahan A. (2021). Do hermetic storage technologies significantly abate losses of rice over time? An economic evaluation, Int. J. Manag. Account. 3(3), 52-59. https://doi.org/10.34104/ijma.021.052059 @ @ 